[Article]

\title{
亚临界和超临界二氧化碳-甲醇混合气相及液相区中 甲醇核磁弛豫速率比较研究
}

\author{
程晓蒙李 宇陈 总 李宏平 ${ }^{*}$ 郑晓芳 \\ (郑州大学化学与分子工程学院, 郑州 450001)
}

\begin{abstract}
摘要: 用核磁共振氢谱测量了不同温度 $(293.15$ 和 $308.15 \mathrm{~K}$ )及压力高达 $25 \mathrm{MPa}$ 下二氧化碳-甲醇混合气相 (超临界)及液相区 (亚临界)中甲醇(羟基及甲基)的纵向弛豫时间 $T_{1, \text {,xp }}$ 。本工作的目的是考察近临界区二氧化 碳-甲醇混合物的压力、温度及组成对甲醇弛豫速率的影响, 揭示混合物不同相区(气相及液相区)中自旋-晶 格驰豫(SLR)过程的机理。此外, 还对比研究了等温条件下超临界和亚临界混合气相及液相区中甲醇的 SLR

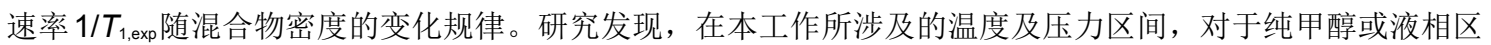
其 SLR 过程是以偶极-偶极(DD)作用机理为主导, 而在气相区 SLR 过程则是以自旋-转动(SR)作用机理占优 势, 也即, 超临界和亚临界二氧化碳-甲醇混合物的 SLR 过程在不同相区有不同的作用机理控制。由于甲醇

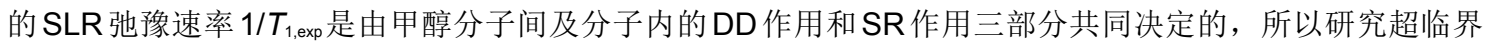
和亚临界二氧化碳-甲醇混合物的 SLR 驰豫速率随压力、浓度及温度的变化规律有助于提供更多该混合物不 同相态区分子间相互作用的动态学信息。
\end{abstract}

关键词: 二氧化碳-甲醇混合物; 偶极-偶极作用机理; 亚临界和超临界流体; 自旋-晶格弛豫速率; 自旋-转 动作用机理

中图分类号 : 0645

\section{A Comparative Study on the NMR Relaxation of Methanol in Sub- and Super-Critical Mixtures of $\mathrm{CO}_{2}$ and Methanol}

\author{
CHENG Xiao-Meng LI Yu CHEN Zong LI Hong-Ping* ZHENG Xiao-Fang \\ (College of Chemistry and Molecular Engineering, Zhengzhou University, Zhengzhou 450001, P. R. China)
}

\begin{abstract}
H}$ NMR longitudinal relaxation times ( $T_{1, \mathrm{exp}}$ of the hydroxyl and methyl group) of methanol in supercritical and subcritical gas-like and liquid-like $\mathrm{CO}_{2}+$ methanol mixtures were obtained as a function of pressure up to $25 \mathrm{MPa}$ and at 293.15 and $308.15 \mathrm{~K}$, respectively. This study was designed to investigate the mechanism of the spin-lattice relaxation (SLR) time $T_{1}$ in different phase regions of $\mathrm{CO}_{2}+$ methanol as homogenous gas-like, and liquid-like mixtures, and the influence of pressure, temperature, and composition on the relaxation rate was examined. Moreover, the density dependent isotherms of the SLR rates $1 / T_{1, \text { exp }}$ were comparatively studied between gas-like and liquid-like binary mixtures. There exists an obvious phase dependent SLR mechanism within the temperature and pressure range carried out herein, that is, the SLR process is dominated by the dipole-dipole (DD) interaction mechanism for both liquid-like mixture and methanol, whereas by the spin-rotation (SR) mechanism for gas-like mixture. Measurement of nuclear magnetic relaxation times can offer micro-dynamic and micro-structural information and are very useful for the study of fluids of strongly
\end{abstract}

Received: July 14, 2016; Revised: August 3, 2016; Published online: August 12, 2016.

${ }^{*}$ Corresponding author. Email: lihongping@zzu.edu.cn; Tel: +86-371-67781205.

The project was supported by the National Natural Science Foundation of China (21543009, 21073167, J1210060), and Innovative Research Grant for Undergraduate Students of National/Zhengzhou University, China (201410459047, 201510459046, 2016xjxm259).

国家自然科学资金(21543009, 21073167, J1210060)和国家级、郑州大学大学生创新训练计划(201410459047, 201510459046, 2016xjxm259)资 助项目

(c) Editorial office of Acta Physico-Chimica Sinica 
interacting molecules. Mutual influence of electric dipoles as well as hydrogen bonds helps determine the structure of the fluid and its molecular dynamics. The present work increases our knowledge of molecular dynamics of alcohols in sub- and supercritical $\mathrm{CO}_{2}$.

Key Words: $\mathrm{CO}_{2}$-methanol mixture; Dipole-dipole interaction mechanism; Subcritical and supercritical fluid; Spin-lattice relaxation rate; Spin-rotation mechanism

\section{Introduction}

Scientists have paid more attention to near critical fluids (NCFs) and supercritical fluids $(\mathrm{SCFs})^{1-4}$, and $\mathrm{NCF} / \mathrm{SCF}$ s can be used in many processes, such as chemical reactions $\mathrm{s}^{2,4-7}$, extraction and fractionation $^{8,9}$, and material processing ${ }^{8,10,11}$. The eco-friendly $\mathrm{NCF}$ /SCFs can be employed as ideal solvent media to substantially replace organic solvents while simultaneously reducing the environmental burden of a given process. Moreover, NC/SC technologies possess many advantages, which will solve more challenging problems after our fundamental knowledge of NCFs/ SCFs improves. As we know, the practical application systems are usually mixtures, and the mixtures near the critical region behave much differently from those in other phase regions. However, some important issues should be further examined. For instance, how do the properties of a subcritical fluid differ quantitatively from those of a SCF near the critical region? How do the microdynamics and micro-structure of the components influence the properties of the fluids near the critical region?

It is well known that the features of the NCFs/SCFs are originated from their specific intermolecular interactions. Different methods have been introduced to study those interactions in NCFs/ SCFs, such as spectroscopy ${ }^{6,71,12,13}$, simulation ${ }^{14,15}$, calorimetry ${ }^{16,17}$, and small-angle X-ray scattering (SAXS) ${ }^{18,19}$. Among them, spectroscopic investigations of model systems as $\mathrm{CO}_{2}$-alkanol on thermodynamic and molecular dynamic background represent a current research area. Thus far $\mathrm{CO}_{2}$-methanol fluids, a scientifically interesting and a technologically important class of mixed solvents have enjoyed the most attention, and a number of authors have reported vibrational spectroscopy ${ }^{20-23}$, NMR spectroscopy ${ }^{24-31}$, absorption and emission spectra ${ }^{13}$ as well as molecular dynamics simulation $^{14}$ on such systems. Meanwhile, NMR spectroscopy is regarded as a very informative method to probe the properties of fluids on a microscopic level, and NMR spectroscopy at NCFs/ SCFs conditions also has potential applications in the studies of hydrogen bonds or reaction monitoring ${ }^{24}$ as molecular structural changes induced by pressure on hydrogen bonds are also very interesting topics. Moreover, measurement of nuclear magnetic relaxation times can offer micro-dynamic and micro-structural information and are thus very useful for the study of fluids of strongly interacting molecules. In $\mathrm{CO}_{2}$-methanol mixture, mutual influence of electric dipoles as well as hydrogen bonds on the nuclear magnetic relaxation times helps reveal the structure of the fluid and its molecular dynamics. The ${ }^{13} \mathrm{C}$ nuclear spin-lattice relaxation (SLR) studies on $\mathrm{CO}_{2}(1)+$ methanol(2) were made at supercritical conditions by Grant group ${ }^{25,32}$, one work focused on the $\mathrm{CO}_{2}$ clustering ${ }^{25}$, and another studied hydrogen bonding of methanol in supercritical $\mathrm{CO}_{2}\left(\mathrm{ScCO}_{2}\right)^{32}$. However, the data were from a relatively narrow range of states (only one composition $x_{2}=$ 0.042 was examined) to investigate temperature $\left(288-348 \mathrm{~K}^{25}\right.$, $\left.287-334 \mathrm{~K}^{32}\right)$, pressure $(8.0-20.0 \mathrm{MPa})$ and density effects on the SLR processes. The ${ }^{1} \mathrm{H}$ NMR longitudinal relaxation times $\left(T_{1}{ }^{\text {obs }}\right)$ of water in $\mathrm{ScCO}_{2}$ were examined as a function of water density (313.3 K, 10 and $20 \mathrm{MPa}$ ) by Kanakubo and coworkers, and they found that $1 / T_{1}^{\text {obs }}$ linearly decreased with increasing water density up to approximate $12 \mathrm{~mol} \cdot \mathrm{m}^{-3}$ and then kept unchanged at higher density $^{33}$. Many nuclear spin interaction mechanisms may affect the longitudinal relaxation times $\left(T_{1}\right)$ values, among them, the spinrotation (SR) and the dipole-dipole (DD) mechanisms are the most important ones in the sub- and supercritical $\mathrm{CO}_{2}$ mixtures ${ }^{25}$. Nevertheless, such topic as how the SLR processes may differ in subcritical or supercritical gas-like and liquid-like regions remains little explored. Hence in this work, the ${ }^{1} \mathrm{H}$ NMR longitudinal relaxation times of methanol in sub- and supercritical $\mathrm{CO}_{2}$ were obtained as a function of pressure and temperature, respectively. The present work will help readers to understand the mechanism of the SLR time in different phase regions of $\mathrm{CO}_{2}$-methanol as homogenous gas-like, and liquid-like mixtures (the vapor-liquid equilibria (VLE) data are shown in Scheme $1^{34,35}$ ). We demonstrate herein that there exists an obvious phase dependent SLR mechanism within the temperature and pressure range carried out

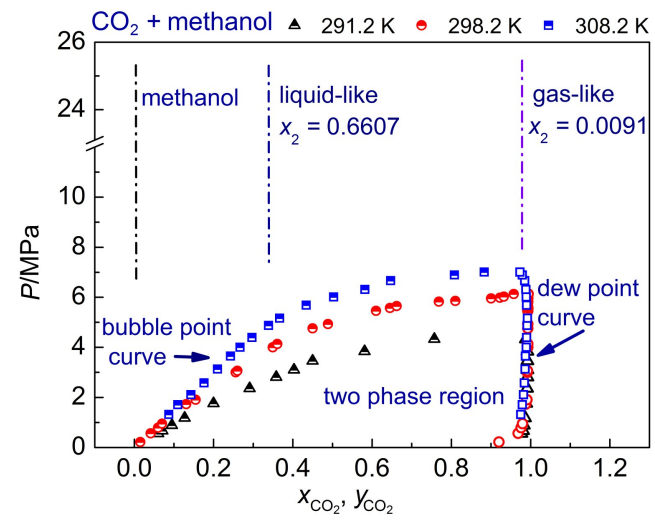

Scheme 1 Schematic representation of the mixtures of

$\mathrm{CO}_{2}(1)+$ methanol(2) in different phase regions

Herein, gas-like and liquid-like mixtures refer to supercritical and subcritical fluid, respectively, at the experimental conditions under study. The VLE data of the mixture of $\mathrm{CO}_{2}+$ methanol at $291.2 \mathrm{~K}$ (triangles) and $308.2 \mathrm{~K}$ (squares) are from Chang and coworkers ${ }^{34}$, and the data of $298.2 \mathrm{~K}$ (circles) are from Brunner and coworkers ${ }^{35}$. The experimental VLE data of the mixture at $293.2 \mathrm{~K}$ could not be found, and the reference critical pressure of the mixture at $293.2 \mathrm{~K}$, $P_{\text {c,mix }}(293.2 \mathrm{~K})$, can be estimated to be lower than $6.23 \mathrm{MPa}\left[P_{\mathrm{c} \text {,mix }}(298.2 \mathrm{~K})\right]^{35}$. $x$ and $y$ denote the mole fractions of liquid and gas phase of the mixture, respectively. And $x_{2}$ represents the mole fraction of methanol. 
herein, that is, the SLR process is dominated by the DD mechanism in both subcritical liquid-like mixture and methanol, whereas by the SR mechanism in supercritical gas-like mixture. We also find what is the most sensitive dynamic variable to probe or reflect the hydrogen bond information between methanol molecules in near critical $\mathrm{CO}_{2}$ mixtures. The present study is sure to broaden our knowledge of molecular dynamics in near critical $\mathrm{CO}_{2}$-alkanol systems.

\section{Experimental}

The ${ }^{1} \mathrm{H}$ NMR spectra were recorded by a Varian Unity Inova $400 \mathrm{MHz}$ NMR spectrometer (USA) with a SFC NMR flow probe described by Maiwald and coworkers ${ }^{24}$. $\mathrm{CO}_{2}$ (purity higher than 99.995\%, Messer-Griesheim, Germany) and methanol (HPLC grade, purity higher than $99.9 \%$, Merck, Darmstadt, Germany) were used as received. A standard inversion recovery pulse sequence was used to measure the spin-lattice relaxation times. The densities of mixtures were measured by a vibrating tube densimeter (Anton Paar, DMA 512 P, Austria). The pressure was measured by a pressure transducer (HKM-375M-350 bar SG, Kulite Semi Conductor Products, Leonia, USA), and the temperature was kept constant by a Thermo Haake C41P and K20 thermostat (Germany) for NMR and densimeter, respectively. Details about the experimental setup, sample preparation as well as the density measurements were described previously ${ }^{24}$. The SLR time measurements were made in this work on methyl and hydroxyl protons of methanol in $\mathrm{CO}_{2}$ mixtures, respectively. Thus the relaxation data will reflect both the methyl and hydroxyl group dynamics and their change with temperature, pressure and density of fluid. The VLE data of $\mathrm{CO}_{2}$ and methanol mixture at different temperatures are illustrated in Scheme 1. The critical parameters of the binary mixture at $308.15 \mathrm{~K}$ are critical composition $\left(x_{\mathrm{C}_{2} \mathrm{CO}_{2}}\right)$ in the range of $0.883-0.973$ and critical pressure $\left(P_{\mathrm{c}, \text { mix }}\right)$ of 7.01 $\mathrm{MPa}^{34}$, respectively. Although we could not find the exact value of $P_{\mathrm{c}, \text { mix }}$ at $293.15 \mathrm{~K}$, we know that $P_{\mathrm{c}, \text { mix }}(293.15 \mathrm{~K})$ should fall in between $P_{\mathrm{c}, \text { mix }}(291.15 \mathrm{~K})$ and $P_{\mathrm{c} \text {, mix }}(298.15 \mathrm{~K})$. Since the estimated $P_{\mathrm{c}, \text { mix }}$ at 291.2 and $298.2 \mathrm{~K}$ are $4.33 \mathrm{MPa}^{34}$ and $6.23 \mathrm{MPa}$ (with $\left.x_{\mathrm{C}, \mathrm{CO}_{2}}=0.9693\right)^{35}$, respectively, the value of $P_{\mathrm{c}, \text { mix }}(293.15 \mathrm{~K})$ is sure to be within the range of $4.33-6.23 \mathrm{MPa}$ or lower than $6.23 \mathrm{MPa}$. Herein, the pressures must be finely controlled to ensure the mixtures being in single phase regions, and the gas-like and liquidlike mixtures (as illustrated in Scheme 1) refer to super- and subcritical fluids, respectively, at the experimental conditions under study (temperature at two isotherms of 293.15 and $308.15 \mathrm{~K}$; pressures from $P_{\text {low }}$ up to $25 \mathrm{MPa}$, and the value of $P_{\text {low }}$ was selected to be higher than the critical pressure of the mixture under investigation).

In the present work, the ${ }^{1} \mathrm{H}$ SLR times of both methyl $T_{1, \text { exp }}\left(\mathrm{CH}_{3}\right)$ and hydroxyl groups $T_{1, \exp }(\mathrm{OH})$ of methanol in near critical $\mathrm{CO}_{2}$ have been determined over a range of pressure up to $25 \mathrm{MPa}$ at two isotherms of 293.15 and $308.15 \mathrm{~K}$ and along three isopleths (shown in Scheme 1), which corresponded to the methanol mole fraction of $x_{2}=0.0091$ (supercritical gas-like mixture), 0.6607 (subcritical liquid-like mixture), and 1.0 (pure liquid methanol). Hereof, for the binary mixture under study, critical fluid refers to a fluid with critical composition and a pressure above the critical pressure, whereas subcritical fluids mean homogenous fluids above the bubble-point curve ${ }^{16}$, as illustrated in Scheme 1.

\section{Results and discussion}

The measured ${ }^{1} \mathrm{H}$ relaxation rate, $1 / T_{1, \text { exp }}$, has three possible contributions from intermolecular DD $\left(T_{1, \text { inter }}^{\mathrm{DD}}\right)$, intramolecular DD $\left(1 / T_{1, \text { intra }}^{\mathrm{DD}}\right)$, and SR interactions $\left(1 / T_{1}^{\mathrm{SR}}\right)$, which is given by Eq. $(1)^{36}$ :

$$
1 / T_{1, \text { exp }}=1 / T_{1, \text { inter }}^{\mathrm{DD}}+1 / T_{1, \text { intra }}^{\mathrm{DD}}+1 / T_{1}^{\mathrm{SR}}=1 / T_{1}^{\mathrm{DD}}+1 / T_{1}^{\mathrm{SR}}
$$

Under the "extreme narrowing approximation", the given relaxation rates can be approximated as ${ }^{33,36}$

$$
\begin{aligned}
& 1 / T_{1, \text { intra }}^{\mathrm{DD}} \propto \tau_{\mathrm{r}} \\
& 1 / T_{1, \text { inter }}^{\mathrm{DD}} \propto \frac{1}{D_{\mathrm{t}}} \propto \tau_{\text {trans }} \\
& 1 / T_{1}^{\mathrm{SR}} \propto T \tau_{\mathrm{J}}
\end{aligned}
$$

$\tau_{\mathrm{r}}, \tau_{\text {trans }}$, and $D_{\mathrm{t}}$ represent the rotational correlation time, the translational correlation time, and the translational diffusion coefficient, respectively. $\tau_{\mathrm{J}}$ is the angular momentum correlation time and $T$ the thermodynamic temperature. Herein, $\tau_{\mathrm{J}}$ corresponds to the average time between collisions leading to the angular momentum energy transfer. We expect that as density of the mixture increases, the collision between solute molecules become frequent, which will shorten the angular momentum correlation time, that is, $1 / T_{1}^{\mathrm{SR}}$ of the solute molecules. So the spin-rotational interactions are thought to be molecular collision frequencies dependent, which closely relates to those macroscopic properties such as temperature and density of fluid, whereas the dipolar interactions are temperature and fluid viscosity dependent. As the viscosity of fluid could be expressed as a function of density, the above two correlation times $\left(T_{1}^{\mathrm{SR}}\right.$ and $\left.T_{1}^{\mathrm{DD}}\right)$ thus can be treated as functions of densities of the fluid, and then the experimental relaxation rate $\left(1 / T_{1, \text { exp }}\right)$ is certainly dependent on density and temperature according to the relationship shown in Eq.(1). In the following sections, we will distinguish between the spin-rotational and the dipolar contributions to the relaxation rate, and see how the SLR processes behave in different near critical regions, and explore whether there exists any dominant contributions in near critical gas-like and liquid-like regions.

\subsection{Density and temperature dependence of spin- lattice relaxation rate $\left(1 / T_{1, \exp }\right)$ of both methyl $\left[1 / T_{1, \exp }\left(\mathrm{CH}_{3}\right)\right]$ and hydroxyl groups $\left[1 / T_{1, \exp }(\mathrm{OH})\right]$ of methanol in sub- and super-critical mixture of $\mathrm{CO}_{2}$ and methanol}

The dominance of one of the two relaxation mechanisms under consideration can be easily recognized due to their different density (or concentration) ${ }^{33}$ and temperature dependence ${ }^{37}$. Firstly, the density dependence of $1 / T_{1, \text { exp }}$ : it is expected that the collision frequency of methanol molecules in mixture will be enhanced as the density of mixture $\left(\rho_{\text {mix }}\right)$ increases, which will shorten the $\tau_{\mathrm{J}}$, thus leads to a reduction in $1 / T_{1}^{\mathrm{SR}}$ of methaol molecules. Therefore, a negative slope of $1 / T_{1, \exp }$ with $\rho_{\text {mix }}$ is typical for a dominating SR 
relaxation according to Eqs.(1) and (3), and it is the case for gas like mixtures $\left(x_{2}=0.0091\right)$ as shown in Figs.1 and 2. Concerning the liquid like mixture $\left(x_{2}=0.6607\right)$ and methanol $\left(x_{2}=1.0\right)$, the association degree of hydrogen bond is promoted as $\rho_{\text {mix }}$ increases $^{38}$, then both the rotational and translational motions of methanol in near critical $\mathrm{CO}_{2}$ will be slowed down ${ }^{33}$. In other words, $\tau_{\mathrm{r}}$ and $1 / D_{\mathrm{t}}$ increase with $\rho_{\text {mix }}$. And if DD contribution is predominant, $\tau_{\mathrm{r}}$ and $D_{\mathrm{t}}$ of methanol in near critical $\mathrm{CO}_{2}$ should play an important role in the intramolecular relaxation time $\left(T_{1, \text { intra }}^{\mathrm{DD}}\right)$ and the intermolecular relaxation time $\left(T_{1, \text { inter }}^{\mathrm{DD}}\right)$, respectively ${ }^{33}$, which brings about a positive slope of $1 / T_{1, \exp }$ with $\rho_{\text {mix }}$ according to Eqs. (1) and (2). Secondly, the temperature influence on $1 / T_{1, \text { exp }}$ : as can be seen from Hubbard's relation ${ }^{39}$ and Eq.(3), both $\tau_{\mathrm{J}}$ and the SR relaxation rate $1 / T_{1}^{\text {sR }}$ increase with increasing temperature, whereas $\tau_{\mathrm{r}}$ and $\tau_{\text {trans }}$ and thus the DD relaxation rates, decrease with increasing temperature ${ }^{36}$. Briefly, the relaxation rate $1 / T_{1, \text { exp }}$ decreases simultaneously with increasing $\rho_{\text {mix }}$ and decreasing temperature for SR mechanism, whereas for DD mechanism the $1 / T_{1, \text { exp }}$ increases with increasing $\rho_{\text {mix }}$ and decreasing temperature ${ }^{33,36,37}$.

\subsection{Phase dependent relaxation mechanisms in sub- and super-critical $\mathrm{CO}_{2}+$ methanol mixtures}

If both relaxation mechanisms contribute with the same amount in gas-like mixture, then in the density dependence of $1 / T_{1, \mathrm{exp}}$ the sign of the slope may change and a minimum occurs, so does it for liquid-like mixture. However, the observed monotonous linear density dependences of $1 / T_{1, \text { exp }}$ in Figs. 1 and 2 indicate that only one relaxation contribution is possibly predominant in gas-like and liquid-like regions, respectively. The phase regions of the dominance of the DD and of the SR relaxation under consideration can be clearly demonstrated ${ }^{37}$ with a diagram as Fig.1, showing the total relaxation rate $1 / T_{1, \text { exp }}\left(\mathrm{CH}_{3}\right)$ as a function of temperature and $\rho_{\text {mix }}$. It is evident from Fig.1, a negative density dependence of $1 / T_{1, \exp }\left(\mathrm{CH}_{3}\right)$ at the two isotherms in gas-like regions suggests a dominant SR contribution to the overall SLR at this region,

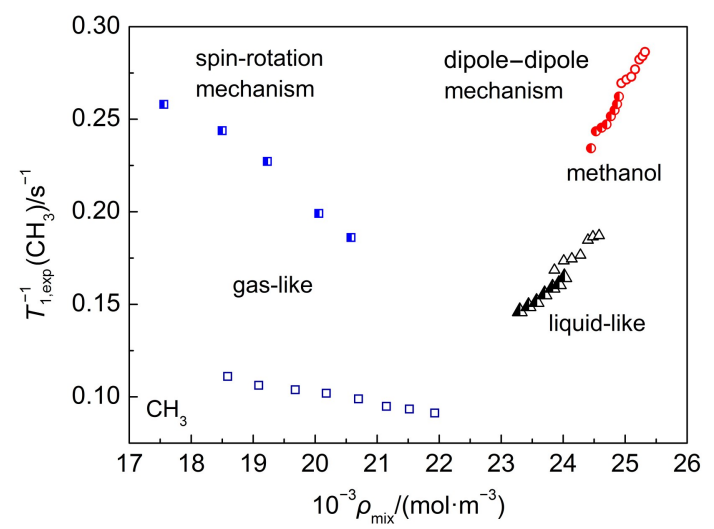

Fig.1 Experimental relaxation rate of methyl group 1/ $T_{1, \text { exp }}\left(\mathrm{CH}_{3}\right)$ isotherms (for methanol in $\mathrm{CO}_{2}$ ) in different phase regions plotted in dependence of density of $\mathrm{CO}_{2}(1)+$ methanol(2) mixtures

Open and half-closed symbols represent 293.15 and $308.15 \mathrm{~K}$, and squares, triangles and circles represent gas-like mixture $\left(x_{2}=0.0091\right)$, liquid-like mixture $\left(x_{2}=0.6607\right)$ and methanol $\left(x_{2}=1.0000\right)$, respectively. The uncertainty of $T_{1, \text { exp }}\left(\mathrm{CH}_{3}\right)$ is $0.0001 \mathrm{~s}, u(T)=0.01 \mathrm{~K}, u\left(x_{2}\right)=0.0002$ and $u_{\mathrm{c}}\left(\rho_{\text {mix }}\right)=0.1 \mathrm{~mol} \cdot \mathrm{m}^{-3}$

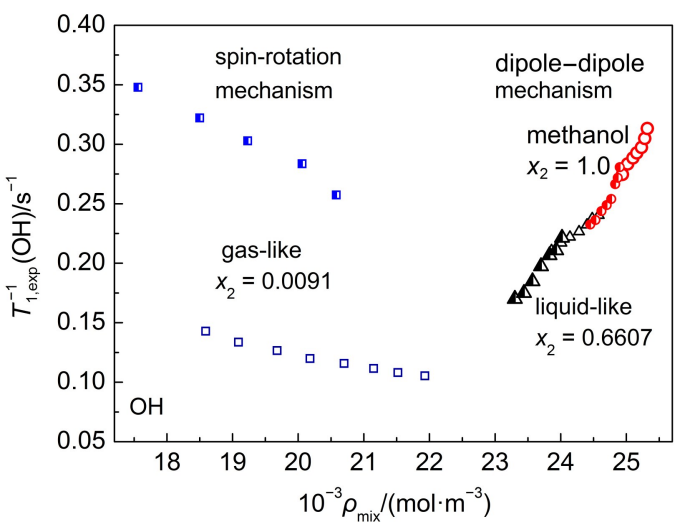

Fig.2 Spin lattice relaxation rate of hydroxyl group $1 / T_{1, \text { exp }}(\mathrm{OH})$ isotherms as a function of density of $\mathrm{CO}_{2}(1)+$ methanol(2) mixtures

Open and half-closed symbols represent 293.15 and $308.15 \mathrm{~K}$, and squares, triangles and circles represent gas-like mixture $\left(x_{2}=0.0091\right)$, liquid-like mixture $\left(x_{2}=0.6607\right)$ and methanol $\left(x_{2}=1.0\right)$, respectively. The uncertainty of $T_{1, \text { exp }}(\mathrm{OH})$ is $0.0001 \mathrm{~s}, u(T)=0.01 \mathrm{~K}, u\left(x_{2}\right)=0.0002$ and $u_{\mathrm{c}}\left(\rho_{\text {mix }}\right)=0.1 \mathrm{~mol} \cdot \mathrm{m}^{-3}$.

whereas a positive density dependence of $1 / T_{1, \text { exp }}\left(\mathrm{CH}_{3}\right)$ at the two isotherms reflects that the DD interactions predominate the relaxation process for both liquid-like mixture and methanol. A similar trend was also observed in Fig.2 for the rate of hydroxyl group, the values of $1 / T_{1, \text { exp }}(\mathrm{OH})$ linearly decrease with increasing density in gas-like mixture $\left(x_{2}=0.0091\right)$ whereas linearly increase with the increase in density for both liquid-like mixtures $\left(x_{2}=\right.$ $0.6607)$ and methanol.

The spin-lattice relaxation time of hydroxyl group $T_{1, \text { exp }}(\mathrm{OH})$ and methyl group $T_{1, \text { exp }}\left(\mathrm{CH}_{3}\right)$ isotherms as a function of pressure for near critical $\mathrm{CO}_{2}+$ methanol mixtures including gas-like mixture $\left(x_{2}=0.0091\right)$, liquid-like mixture $\left(x_{2}=0.6607\right)$ and methanol $\left(x_{2}=\right.$ 1.0) are shown in Figs.3-6, respectively. As it can be seen from Figs.3 -6 , the pressure dependence of relaxation times of hydroxyl group at the isotherms resembles that of the methyl group. We believe that the observed density dependence of $1 / T_{1, \text { exp }}$ reveals a

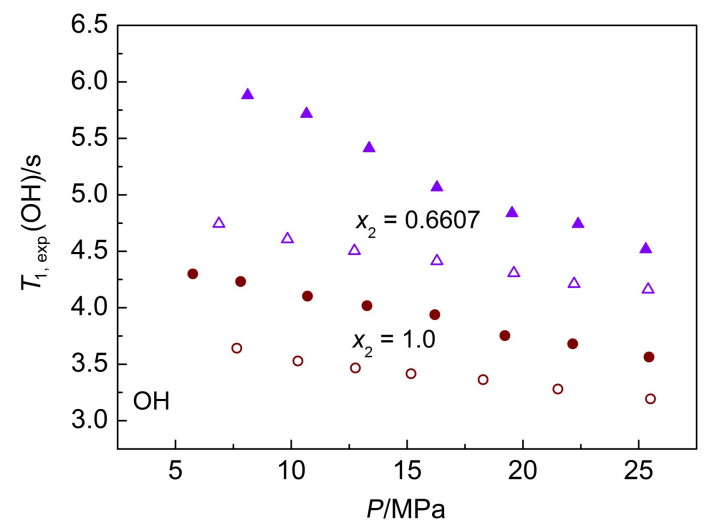

Fig.3 Spin-lattice relaxation time of hydroxyl group $T_{1, \text { exp }}(\mathrm{OH})$ isotherms as a function of pressure for liquid-like $\mathrm{CO}_{2}(1)+$

methanol(2) mixtures $\left(x_{2}=0.6607\right.$, triangles) and methanol $\left(x_{2}=1.0\right.$, circles $)$

Open and closed symbols represent 293.15 and $308.15 \mathrm{~K}$, respectively. The uncertainty of $T_{1, \mathrm{exp}}(\mathrm{OH})$ is $0.0001 \mathrm{~s}, u(T)=0.01 \mathrm{~K}$, $u(P)=0.001 \mathrm{MPa}, u\left(x_{2}\right)=0.0002$. 


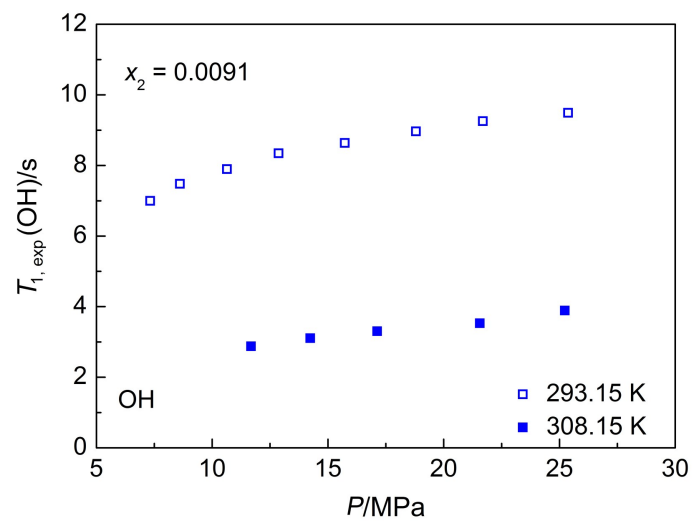

Fig.4 Spin-lattice relaxation time of hydroxyl group $T_{1, \text { exp }}(\mathrm{OH})$ isotherms as a function of pressure for gas-like $\mathrm{CO}_{2}(1)+$ methanol(2) mixture $\left(x_{2}=0.0091\right)$

Open and closed squares represent 293.15 and $308.15 \mathrm{~K}$, respectively. The uncertainty of $T_{1, \text { exp }}(\mathrm{OH})$ is $0.0001 \mathrm{~s}, u(T)=0.01 \mathrm{~K}$, $u(P)=0.001 \mathrm{MPa}, u\left(x_{2}\right)=0.0002$

structural change in the hydrogen bonding between methanol molecules in mixtures. The degree of hydrogen bonding association between methanol molecules is stronger in pure methanol than that in liquid-like mixture ${ }^{38}$ at constant temperature, which will slow down the rotational and translational motion of methanol, that is, a larger rise is expected in $\tau_{r}$ and $1 / D_{t}$ values with increasing density or pressure for pure methanol compared with liquid-like mixture, therefore at constant temperature, the results of $1 / T_{1, \exp }\left(x_{2}=1.0\right)>1 / T_{1, \exp }\left(x_{2}=0.6607\right)$ (Figs. 1 and 2$)$ or $T_{1, \exp }\left(x_{2}=\right.$ $1.0)<T_{1, \text { exp }}\left(x_{2}=0.6607\right)$ (Figs.3 and 5) can be reasonably explained under DD mechanism based on the formulae shown in Eqs.(1) and (2). As to the temperature dependence of relaxation time at constant methanol mole fraction, the higher the temperature, the less amount of hydrogen bonding in mixture, then both the rotational and translational motions of methanol in near critical $\mathrm{CO}_{2}$ get accelerated with increasing temperature ${ }^{33}$. That is, the value of $\tau_{\mathrm{r}}$

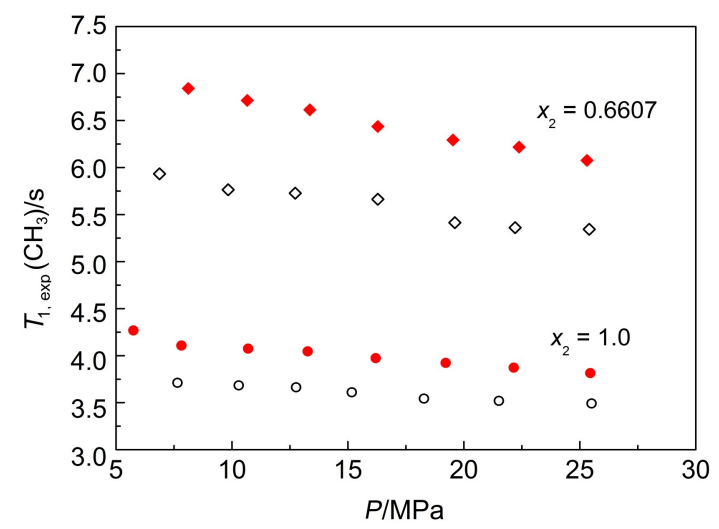

Fig.5 Spin-lattice relaxation time of methyl group $T_{1, \text { exp }}\left(\mathrm{CH}_{3}\right)$ isotherms as a function of pressure for liquid-like $\mathrm{CO}_{2}(1)+$ methanol(2) mixture $\left(x_{2}=0.6607\right.$, diamonds) and methanol $\left(x_{2}=1.0000\right.$, circles $)$

Open and closed symbols represent 293.15 and $308.15 \mathrm{~K}$, respectively. The uncertainty of $T_{1, \exp }\left(\mathrm{CH}_{3}\right)$ is $0.0001 \mathrm{~s}, u(T)=0.01 \mathrm{~K}$, $u(P)=0.001 \mathrm{MPa}, u\left(x_{2}\right)=0.0002$. and $\tau_{\text {trans }}$ will decrease with increasing temperature, which directly results in an increase in the value of $T_{1}^{\mathrm{DD}}$ with increasing temperature according to Eq.(2). As exhibited in Figs.3 and 5, the temperature dependence of the relaxation time as $T_{1, \exp }(308.15 \mathrm{~K})>$ $T_{1, \text { exp }}(293.15 \mathrm{~K})$ represents a characteristic DD-dominant mechanism in liquid-like region. Similarly, $\tau_{\mathrm{s}}$ increases with increasing temperature $^{39}$, which leads to a decline in $T_{1}^{\mathrm{SR}}$ following a rise in temperature according to Eq.(3). In other words, the temperature tendency of $T_{1, \text { exp }}(308.15 \mathrm{~K})<T_{1, \text { exp }}(293.15 \mathrm{~K})$ in gas-like region (Figs.4 and 6) agrees with a feature of a SR-dominant mechanism.

\subsection{Correlation of spin-lattice relaxation rate of hydroxyl group $\left[1 / T_{1, \exp }(\mathrm{OH})\right]$ isotherms in sub- and super-critical $\mathrm{CO}_{2}+$ methanol mixtures}

As it can be seen from Fig.1 and 2, the density dependence of relaxation rates of hydroxyl group at the two isotherms behaves in a similar way as that of the methyl group, and therefore in the following part, we will only pay attention to the relationship between the relaxation rates of hydroxyl group and the density of mixtures.

From Fig.2, we could find that there exists a linear relationship between the density of mixture $\rho_{\text {mix }}$ and the relaxation rate of hydroxyl group $1 / T_{1, \text { exp }}(\mathrm{OH})$, and then the data of $1 / T_{1, \text { exp }}(\mathrm{OH})$ were correlated with the $\rho_{\text {mix }}$ data using a linear regression equation given by

$1 / T_{1, \text { exp }}(\mathrm{OH})=A_{0}+A_{1} \rho_{\text {mix }}$

For both methanol $\left(x_{2}=1.0000\right)$ and liquid-like mixture $\left(x_{2}=\right.$ $0.6607)$, as the temperature impact upon $1 / T_{1, \operatorname{xxp}}(\mathrm{OH})$ is negligibly small, the weak temperature influence could be neglected, and hence we could merge two isotherms of density dependence of $1 / T_{1, \exp }(\mathrm{OH})$ at 293.15 and $308.15 \mathrm{~K}$ for methanol $\left(x_{2}=1.0000\right)$ and fitted the two isotherms using the same set of parameters. Similarly, we also incorporated the two isotherms of $1 / T_{1, \exp }(\mathrm{OH})-\rho_{\text {mix }}$ pairs at 293.15 and $308.15 \mathrm{~K}$ and simulated them using identical set of parameters for liquid-like mixture $\left(x_{2}=0.6607\right)$. The linear fit results for methanol and the near critical $\mathrm{CO}_{2}(1)+$ methanol(2)

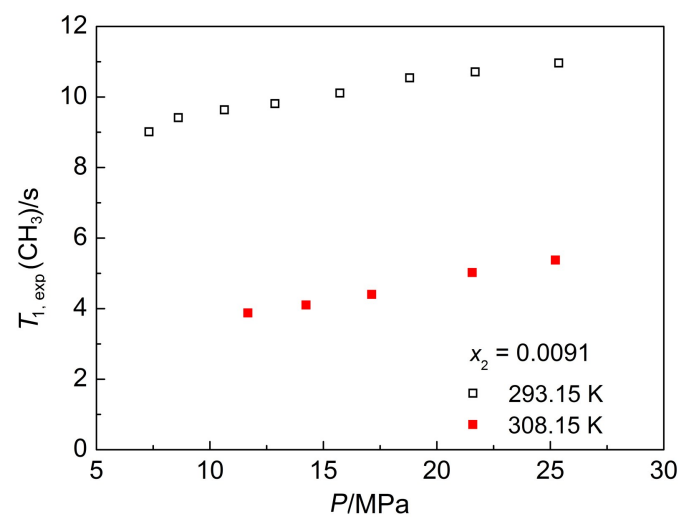

Fig.6 Spin-lattice relaxation time of methyl group $T_{1, \text { exp }}\left(\mathrm{CH}_{3}\right)$ isotherms as a function of pressure for gas-like $\mathrm{CO}_{2}(1)+$ methanol(2) mixture $\left(x_{2}=0.0091\right)$

Open and closed squares represent 293.15 and $308.15 \mathrm{~K}$, respectively. The uncertainty of $T_{1, \exp }\left(\mathrm{CH}_{3}\right)$ is $0.0001 \mathrm{~s}, u(T)=0.01 \mathrm{~K}$, $u(P)=0.001 \mathrm{MPa}, u\left(x_{2}\right)=0.0002$. 
Table 1 Linear fit parameters of Eq.(4) ${ }^{\mathrm{a}}$ for methanol and $\mathrm{CO}_{2}(1)+$ methanol(2) mixtures $^{b}$

\begin{tabular}{|c|c|c|c|c|}
\hline & $A_{0}$ & $A_{1}$ & $R$ & $s$ \\
\hline $\begin{array}{l}x_{2}=1.0000,293.15 \mathrm{~K}, \\
7.65-25.51 \mathrm{MPa} \text { and } \\
x_{2}=1.0000,308.15 \mathrm{~K}, \\
5.75-25.45 \mathrm{MPa}\end{array}$ & -2.010 & 0.092 & 0.976 & 0.004 \\
\hline $\begin{array}{l}x_{2}=0.6607,293.15 \mathrm{~K}, \\
6.88-25.41 \mathrm{MPa} \text { and } \\
x_{2}=0.6607,308.15 \mathrm{~K}, \\
8.12-25.31 \mathrm{MPa}\end{array}$ & -1.139 & 0.056 & 0.960 & 0.004 \\
\hline $\begin{array}{l}x_{2}=0.0091,293.15 \mathrm{~K}, \\
7.32-25.37 \mathrm{MPa}\end{array}$ & 0.344 & -0.011 & 0.977 & 0.002 \\
\hline $\begin{array}{l}x_{2}=0.0091,308.15 \mathrm{~K} \\
11.68-25.23 \mathrm{MPa}\end{array}$ & 0.852 & -0.029 & 0.981 & 0.005 \\
\hline
\end{tabular}

mixtures are tabulated in Table 1 . It is obvious from the $A_{1}$ (slope) values in Table 1 that the relaxation rates in methanol are more sensitive to the density change than that in liquid-like mixture when DD is the predominant relaxation. However, the temperature influence in gas-like mixture $\left(x_{2}=0.0091\right)$ is significant and cannot be ignored, and the relaxation rate correlation was then treated using different fitting parameters for 293.15 and $308.15 \mathrm{~K}$ isotherms, respectively.

In brief, it is found that temperature plays a more important role in the SLR process in gas-like mixture when spin-rotation is the dominant contribution as shown in Figs.1, 2, 4 and 6, whereas pressure or density has considerable impact upon the relaxation time or rate in methanol and liquid-like mixture when dipoledipole mechanism predominates the relaxation process (Table 1, Figs.1-3 and Fig.5). In contrast, the ${ }^{1} \mathrm{H}$ proton longitudinal relaxation times of $\mathrm{H}_{2} \mathrm{O}$ in $\mathrm{ScCO}_{2}$ were studied at $313.3 \mathrm{~K}$ (10 and $20 \mathrm{MPa}$ ) by Kanakubo and coworkers ${ }^{33}$, and they also reported that the relaxation rate decreased linearly with increasing water density up to approximate $12 \mathrm{~mol} \cdot \mathrm{m}^{-3}$ and then kept unchanged at higher density, which agrees well with our assumption that spin-rotation interaction is the predominant mechanism at low concentration or density of the mixture. Since the density dependence of $1 / T_{1, \text { exp }}$ in gas-like regions is mainly spin-rotation mechanism, that means $1 / T_{1, \text { exp }} \propto 1 / T_{1}^{\mathrm{SR}}$, and as we know $1 / T_{1}^{\mathrm{SR}} \propto T \tau_{\mathrm{J}}$, so the above density dependence of $1 / T_{1, \exp }$ reflects a change in $\tau_{\mathrm{J}}$ of methanol in $\mathrm{ScCO}_{2}$, together with the hydrogen bonding between methanol molecules in the mixture. In other words, the angular momentum correlation time $\tau_{\mathrm{s}}$ is a very sensitive variable to probe the hydrogen bonding information between methanol molecules in $\mathrm{ScCO}_{2}$ mixture.

\section{Conclusions}

In summary, the phase dependent relaxation mechanism becomes obvious as $\rho_{\text {mix }}$ is used as variable. The decrease in $\rho_{\text {mix }}$ makes the SLR process switch from dipole-dipole to spin-rotation mechanism, and the transition between the two different relaxation mechanisms as well as their dependence on density and temperature are clearly observed. We demonstrate that the spin-rotation mechanism predominates in gas-like region with significant temperature impact (Figs.1, 2, 4 and 6), whereas the dipole-dipole mechanism is the dominant contribution for both methanol and liquid-like mixture with minor or negligible temperature effect (Figs.1 and 2).

\section{References}

(1) Liu, H. Z.; Jiang, T.; Han, B. X.; Liang, S. G.; Zhou, Y. X. Science 2009, 326, 1250. doi: 10.1126/science. 1179713

(2) Ke, J.; Han, B. X.; George, M. W.; Yan, H. K.; Poliakoff, M. J. Am. Chem. Soc. 2001, 123, 3661. doi: 10.1021/ja003446o

(3) Jessop, P. G.; Subramaniam, B. Chem. Rev. 2007, 107, 2666. doi: $10.1021 / \mathrm{cr} 0401990$

(4) Kajimoto, O. Chem. Rev. 1999, 99, 355. doi: 10.1021/cr9700311

(5) Hou, Z. S.; Han, B. X.; Zhang, X. G.; Zhang, H. F.; Liu, Z. M. J. Phys. Chem. B 2001, 105, 4510. doi: 10.1021/jp003903n

(6) Li, H. P.; Han, B. X.; Liu, J.; Gao, L.; Hou, Z. S.; Jiang, T.; Liu, Z. M.; Zhang, X. G.; He, J. Chem. Eur. J. 2002, 8, 5593. doi: 0947-6539/02/0824-5593

(7) Li, H. P.; Liu, J.; Han, B. X.; Gao, L. Fluid Phase Equilibr. 2002, 200, 111. doi: 10.1016/S0378-3812(02)00021-3

(8) McHugh, M. A.; Kukonis, V. J. Supercritical Fluid Extraction, 2nd ed.; Butterworth-Heinmann: Boston, 1994.

(9) Brunner, G. Gas Extraction: An Introduction to Fundamentals of Supercritical Fluids and their Application to Separation Processes; Steinkopff Darmstadt: New York, 1994.

(10) Cheng, X.; Huang, S.; Li, H.; An, N.; Wang, Q.; Li, Y. RSC Advances 2016, 6, 4545. doi: 10.1039/c5ra25725e

(11) Xue, W.; Qi, L.; Li, X.; Huang, S.; Li, H.; Guan, X.; Bai, G.; Liu, L. E. Chem. Eng. J. 2012, 209, 118. doi: 10.1016/j. cej.2012.08.022

(12) Li, H. P.; Liu, J.; Zhang, H. F.; Wang, S. G.; Han, B. X.; Liu, F. F. J. Supercrit. Fluids 2001, 21, 227. doi: 10.1016/S0896-8446 (01)00097-3

(13) Li, H. P.; Arzhantsev, S.; Maroncelli, M. J. Phys. Chem. B 2007, 111, 3208. doi: 10.1021/jp067916y

(14) Li, H. P.; Maroncelli, M. J. Phys. Chem. B 2006, 110, 21189. doi: $10.1021 / j p 064166 j$

(15) Zhang, X. G.; Han, B. X.; Zhang, J. L.; Li, H. P.; He, J.; Yan, H. K. Chem. Eur. J. 2001, 7, 4237. doi: 0947-6539/01/0719-4237

(16) Li, H. P.; Zhang, X. G.; Han, B. X.; Liu, J.; He, J.; Liu, Z. M. Chem. Eur. J. 2002, 8, 451. doi: 0947-6539/02/0802-0451

(17) Mu, T. C.; Zhang, X. G.; Han, B. X.; Li, H. P.; Liu, J. C.; Wu, W. Z.; Chen, J. W.; Du, J. M. Fluid Phase Equilibr. 2003, 214, 53. doi: 10.1016/S0378-3812(03)00315-7

(18) Zhang, J. L.; Han, B. X.; Zhao, Y. J.; Li, J. S.; Yang, G. Y. Chem. Eur. J. 2011, 17, 4266. doi: 10.1002/chem.201002153

(19) Zhao, Y. J.; Zhang, J. L.; Wang, Q. A.; Li, J. S.; Han, B. X. Phys. Chem. Chem. Phys. 2011, 13, 684. doi: 10.1039/ 
C0CP00869A

(20) Asprion, N.; Hasse, H.; Maurer, G. Fluid Phase Equilbr. 2001, 186, 1. doi: 10.1016/ S0378-3812(01)00363-6

(21) Bai, S.; Yonker, C. R. J. Phys. Chem. A 1998, 102, 8641. doi: 10.1021/jp981302e

(22) Bulgarevich, D. S.; Otake, K.; Sako, T.; Sugeta, T.; Takebayashi, Y.; Kamizawa, C.; Shintani, D.; Negishi, A.; Tsurumi, C. J. Chem. Phys. 2002, 116, 1995. doi: 10.1063/1.1431585

(23) Bulgarevich, D. S.; Sako, T.; Sugeta, T.; Otake, K.; Takebayashi, Y.; Kamizawa, C.; Horikawa, Y.; Kato, M. Ind. Eng. Chem. Res. 2002, 41, 2074. doi: 10.1021/ie0106332

(24) Maiwald, M.; Li, H.; Schnabel, T.; Braun, K.; Hasse, H. J. Supercrit. Fluids 2007, 43, 267. doi: 10.1016/j. supflu.2007.05.009

(25) Bai, S.; Taylor, C. M. V.; Liu, F.; Mayne, C. L.; Pugmire, R. J.; Grant, D. M. J. Phys. Chem. B 1997, 101, 2923. doi: 10.1021/ S1089-5647(96)04048-5

(26) Wallen, S. L.; Palmer, B. J.; Garrett, B. C.; Yonker, C. R. J. Phys. Chem. 1996, 100, 3959. doi: 10.1021/jp9524082

(27) Nikiforov, M. Y.; Lukyanchikova, I. A.; Grechukhin, M. V.; Alper, G. A.; Krestov, G. A. Russ. J. Phys. Chem. 1996, 70, 968.

(28) Ke, J.; Jin, S.; Han, B.; Yan, H.; Shen, D. J. Supercrit. Fluids 1997, 11, 53. doi: 10.1016/ S0896-8446(97)00029-6

(29) Hoffmann, M. M.; Conradi, M. S. J. Phys. Chem. B 1998, 102, 263. doi: $10.1021 /$ jp9726706
(30) Kanakubo, M.; Aizawa, T.; Kawakami, T.; Sato, O.; Ikushima, Y.; Hatakeda, K.; Saito, N. J. Phys. Chem. B 2000, 104, 2749. doi: 10.1021/jp992278n

(31) Bich, E.; Hensen, U.; Michalik, M.; Wandschneider, D.; Heintz, A. Phys. Chem. Chem. Phys. 2002, 4, 5827. doi: 10.1039/ B205242C

(32) Taylor, C. M. V.; Bai, S.; Mayne, C. L.; Grant, D. M. J. Phys. Chem. B 1997, 101, 5652. doi: 10.1021/jp964049w

(33) Kanakubo, M.; Liew, C. C.; Aizawa, T.; Kawakami, T.; Sato, O.; Ikushima, Y.; Hatakeda, K.; Saito, N. Chem. Lett. 2000, 1320. doi: 10.1246/c1.000819

(34) Chang, C. J.; Chiu, K. L.; Day, C. Y. J. Supercrit. Fluids 1998, 12, 223. doi: 10.1016/S0896-8446(98)00076-X

(35) Brunner, E.; Hültenschmidt, W.; Schlichthärle, G. J. Chem. Thermodyn. 1987, 19, 273. doi: 10.1016/0021-9614(87)90135-2

(36) Mussig, S., Franck, E. U.; Holz, M. Zeit. Phys. Chem. (Inter. J. Res. Phys. Chem. Chem. Phys.) 2000, 214, 957. doi: 10.1524/ zpch.2000.214.7.957

(37) McConnell, J. Theory of Nuclear Magnetic Relaxation in Liquids; Cambridge University Press: Cambridge, 1987.

(38) Schnabel, T.; Srivastava, A.; Vrabec, J.; Hasse, H. J. Phys. Chem. B 2007, 111, 9871. doi: 10.1021/jp0720338

(39) Hubbard, P. S. Phys. Rev. 1963, 131, 1155. doi: 10.1103/ PhysRev.131.1155 